\title{
Visualizing Sociomaterial Practice in an ERP Implementation Project
}

\author{
Lei Cui \\ Experimental Teaching Center, Guangdong University of Foreign Studies, Guangzhou, China \\ 418352472@qq.com
}

Keywords: Sociomaterial Practice, ERP, Multidimensional Networks

\begin{abstract}
At the ontological level, a sociomaterial approach which takes equivalent role to technologies and people is attractive, but in the empirical studies, how can we interpret their entanglement is an urgent issue. This article argues that comprehensive use of these theories of Actor Network Theory, Agential Realism and Multidimensional Networks will offer researchers the ability to visualize sociomaterial practice. We involved a longitudinal interpretive study in an Enterprise Resource Planning (ERP) implementation project in china, to show how to visualize sociomaterial practice in an ERP implementation project.
\end{abstract}

\section{Introduction}

The Researches on Technology and Organizing have been going on for more than half a century. In the 1950s, the views on technology in organizational literature were technological determinism, where technology acts as an independent variable on organizational structure. As Perrow [1] advocated: "technology is an independent variable, and structure ... a dependent variable.” During the 1980s, Researchers rejected hard forms of technological determinism, and their studies are labelled by the banner of "social constructivism", where inherent properties of technology do not matter at all and are replaced by a focus on discourse and social constructions [2]. All the two sets of studies share the ontological position that technologies exist separately from people's social structure. Recently, proponents of a sociomaterial approach to studies of technology and organizational structure have begun to provide us with the ontological foundations and theoretical language with which to make this conceptual shift [3-4].

Sociomaterial approach implies that things, technologies, people, and organizations do not have inherently determinate meanings, boundaries, or properties. As Leonardi suggests: "technologies are as much social as they are material and social structures are as much material as they are social [5]. Technologies, people, and organizations are seen as constitutively entangled, implying that we can separate them only analytically. We need to focus on their entanglement to understand how their temporal meanings, boundaries, and properties are continually (re)produced [6]. At the ontological level, a sociomaterial approach which takes equivalent role to technologies and people is attractive, but in the empirical studies, how can we interpret their entanglement.

At the empirical level, it is somewhat problematic of how to separate technologies, people, and organizations and how to demonstrate their entanglement. Leonardi argues that "our current 
understanding of the nature of the relationship between routines and technologies evinces dissonance between our ontological specifications and our empirical observations" [7]. Mueller highlight the methodological uncertainty IS researchers experience when doing research based on the 'sociomateriality' thinking [8]. Jones[9] reviewed 140 journal articles in organization studies and information systems using the term, "sociomateriality", and found that only 31 appears in IS journals and contains empirical work. This demonstrates that the application of the 'Sociomateriality' approach is in its infancy and emerging and that there is room for interpretation.

The theoretical approach of sociomateriality adopted in the information systems field is mainly rooted in Actor Network Theory (ANT), Agential Realism and Multidimensional Networks. ANT has been widely adopted in the information systems (IS) discipline since 1990s. Its ontological stance of symmetry between humans and non-humans and its abundant methods of inquiry are seen to facilitate its practical application in sociomaterial research. Comparing with "weak sociomateriality" for ANT, Agential Realism is viewed as "strong sociomateriality" [9]. Agential Realism implies that there is no pre-existing entities and that "through specific agential intra-actions the boundaries and properties of the components of phenomena become determinate. Multidimensional Networks use the networks to visualize sociomaterial practice. This approach treats networks and technologies as objects that exist separately. Any non-human actor, no matter whether it is a policy, a routine, a chemical, or a drug, can be brought, conceptually, inside a social network, just like a technology. In so doing, the resultant network ceases to be a simple social network. The above three approaches have their own advantages; however, no one has synthesize them in the empirical research of sociomaterial practice.

In this article, we argue that comprehensive use of these theories of ANT, Agential Realism and Multidimensional Networks will offer researchers the ability to visualize sociomaterial practice. Firstly, Agential Realism can help us understand how values, opinions and rhetoric frozen into ERP software were. Secondly, we will show how to use the graphical tools of Multidimensional Networks and concepts of Actor Network Theory to describe the evolution of formal networks. Thirdly, we will use emergent networks to interpret the network translation process. Our research involved a longitudinal interpretive study in an Enterprise Resource Planning (ERP) implementation in china.

The paper is structured as follows. First, we describe the background of the case and research process. Next, in the main section of the paper, we provide a detailed description and analysis of the case, drawing on theories of Agential Realism, ANT and Multidimensional Networks. We discuss the question of how to promote "successful" ERP implementation. Finally, we draw conclusions on how our paper promotes the sociomaterial research at the empirical level.

\section{Research Approach}

An interpretive longitudinal case study method was used. We collected data over a period of one year as the events were taking place in the various phases of the ERP project. The role of the researcher in this study was a consultant, who was invited to investigate the case as a Sample Customer project. This enabled us to gain access to the complex and shifting nature of actions and interpretations (e.g. Documentation about the ERP system planning, implementation and use), we used historical reconstruction from archival documents and recollections of the past for this period, from 2007 to 2008 when the ERP projects were implemented.

\section{Overview of the Case History}

A schematic of the various events and phases of the case study is shown in Figure 1. 


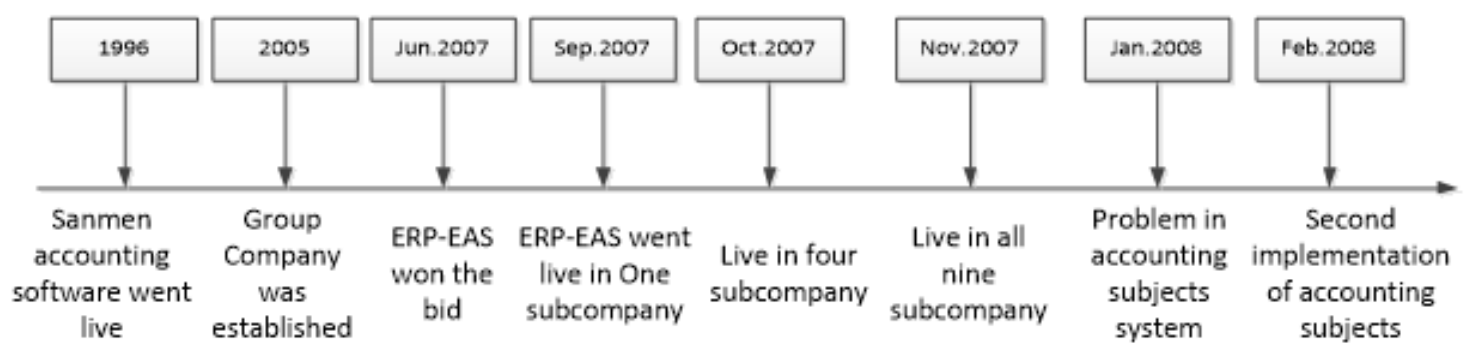

Fig. 1. Events and Phases of the Case

\subsection{Sanmen accounting software went live}

A Province tobacco company was established in 1983. It is state-owned enterprise. It has 14 city companies and 89 County companies. All of these companies use Sanmen accounting software from 1996.

\subsection{Reform of a province tobacco company}

In 2005, the reform of the parent subsidiary company system was implemented in A Province Tobacco Company. The 14 city companies became the wholly owned subsidiary company of A Province Tobacco Company. The original 89 County companies became the marketing department of the city company.

\subsection{ERP-EAS won the bid}

In order to meet the requirements of the new corporate governance system and to strengthen the financial control, A Province Tobacco Company decided to adopt the group company ERP software to meet the requirements of its financial accounting and management.

After the software trial and selection, ERP-EAS software of Kingdee was selected in June 2007. After the selection, A Province Tobacco Company and Kingdee Company have started and staffed the project respectively. The chief financial officer in A company is in charge of the project. One deputy director is the project manager of A company. In Kingdee Company, the vice president is responsible for this project. He nominated an experienced expert as the project manager, and he also formed a consultant team of 10 people.

\subsection{The first stage of the implementation}

According to the characteristics of the implementation process of this case, the implementation process is divided into two stages. The first stage is from September 2007 to November 2007. In these three months, A Province Tobacco Company and its 14 city companies have completed the implementation of the EAS software. The specific implementation process is as follows, firstly the EAS has implemented in one City Company in September 2007. After the system was successfully on-line, then in October 2007 the other four City companies implemented the system successfully, and finally in November 2007 the A Province tobacco company and the remaining nine city companies implemented the system. The entire implementation process was completed within three months. 


\subsection{The second stage of the implementation}

In the second stage, from January 2008 to February 2008, the new group financial software experienced the month and year ending closing. Some accountants found the inconsistencies in some accounting subjects, which resulted in the inability of automatically generating reports in the group level. And they can't do Unified query and association query at the group level. When the deputy director of the provincial company found the problem, he deemed it was a serious problem. So he convened a meeting of the financial directors of each city company and the Kingdee project manager to discuss the problem, finally they determined the accounting subjects system and gave the instruction document. Since the software has been used for a few months, it brought about a lot of implementation work. The work was completed at the end of February 2008.

\section{Case Study}

This section will use the actor network theory and the communication network theory to explain the implementation process of the A group's ERP software, and focus on the evolution process and mechanism the communication network of the first implementation stage.

In the first phase of this ERP implementation project, we can find one formal enrollment network and two emergent networks, which are shown in Fig. 2. The interaction between formal network and emergent network achieves successful translation of actor networks.

\subsection{Analysis of the formal enrollment network}

The key actor is the finance department the provincial corporate. It is represented as N1 in the Fig. 2. They want to realize the centralized financial management and control with the help of EAS software. They use their administrative power to set project goals and establish the immutably mobile point.

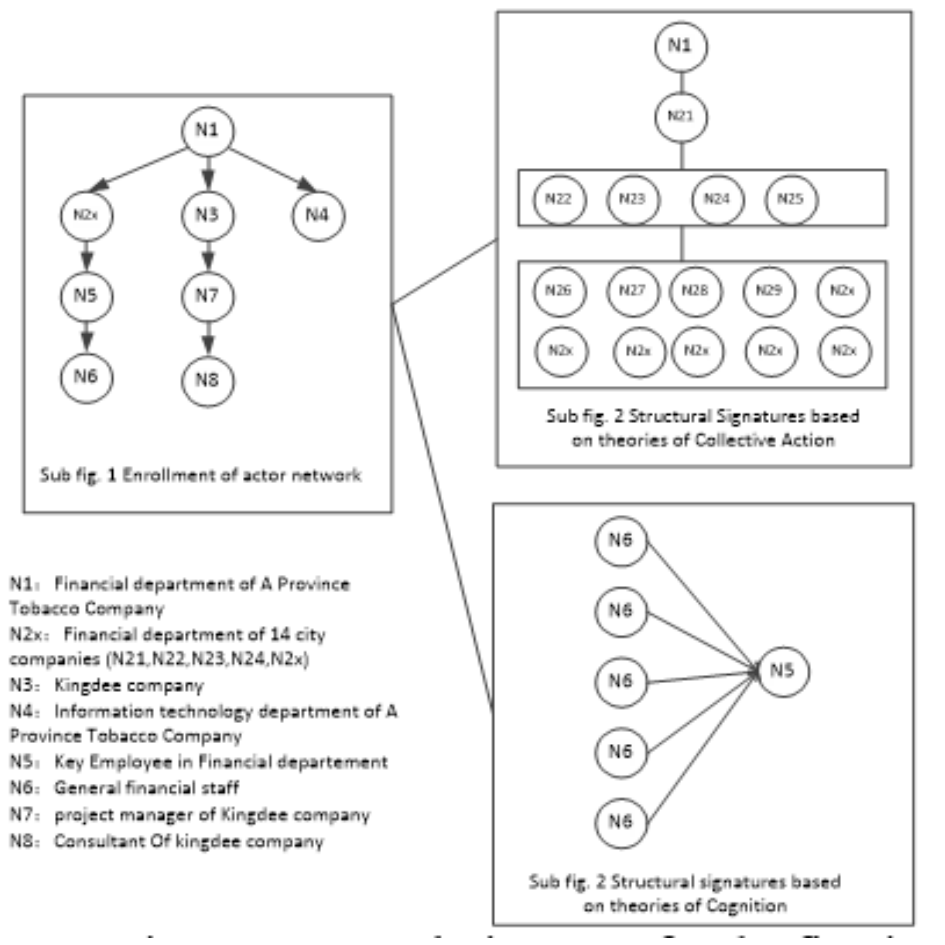

Fig. 2. Structural Signature for the first implementation stage 
After determining the target of translation, the finance department the provincial company started to enroll other actors. First is the financial department of each city, which is represented as N2x in the Fig. 2. Because the city company is a wholly-owned subsidiary of the group company, the provincial company has the absolute administrative power. So they use the administrative order issued by a red head document, and with the reward and punishment system. The chief accountants of each city company signed the letter of responsibility. Then they signed the overall cooperation agreement and the phased implementation of the contract with Kingdee Company, which is represented as N3 in the Fig. 2. The contract made clear the scope and time of implementation, thus increasing the irreversibility of the network. Finally, they communicated with the Information technology department, which is represented as N4 in the Fig. 2, to construct VPN network and server computer.

\subsection{Analysis of the emergent network}

According to Multi-Theoretical Multilevel Models of Multidimensional Networks, we can find two emergent networks in this ERP implement.

According to the empirical study of collective action theory, there is a concept of "threshold" in collective adoption. That is, the number of other adopters that must appear in his network before a person or organization decides to adopt an innovation or new technology. Threshold level determines whether a group can conduct a fast and extensive collective behaviour as a whole. Group A has successfully applied this emergent network theory, as shown in subfigure 2. The implementation process of A group company adopts three steps, the first step is to do a good sample in one a city company. The second step is to do a good sample of the 4 city companies, and finally implemented all other companies. This practice is in line with the theory of collective action. They used sufficient implement resources to ensure a certain amount of adoption in the network, which is the threshold level. It has enhanced the confidence of other city companies about the quality of the software and project schedule. Thus ensuring the success of the project and preventing the risk of failure of all together.

Cognition theory is the perception of the knowledge network where they are. These perceptions reflect the knowledge elements in the network, as well as the relationship between the knowledge storage in the whole network. That is the cognition of the members of the organization on "who knows what" "who knows who knows what".

According to the theory of cognition network, in the implementation of ERP, we should first analyse the cognitive network, and identify members with high network centrality. That is, when people usually consult who when they find software problems. We should train them firstly, and then spread out new technology and knowledge to other person.

Group A has successfully applied this emergent network theory, as shown in subfigure 3.

In the implementation process of the new ERP-EAS software, they first selected the key employee in each financial department, which is represented as N5 in the Fig. 2. They are generally the deputy chief financial officer, the host accounting or the IT technical backbone. These people are the centre of the cognitive network when the original software is used. If there are some problems in the original software, the general financial personnel (N6) often consulted them on how to use and why it was used.

So Kingdee's consultant made plentiful training to these key employees. They not only told them how to use the new software, but also trained them why to use it. So they can use the original cognitive network to drive the implementation process. At the same time, a new cognitive network is set up in the new network to make the internal key personnel (N5) become the centre of the new cognitive network. So that the financial personnel of the city company do not rely too much on the 
ERP implementers of Kingdee company and successfully realized the knowledge transfer.

\section{Discussion}

Reviewing the implementation process of the whole case, we can learn a lot of experience from it. For example, the software is on line in only three months as a whole. After the problems were found, they were corrected in time, and good results have been achieved. We find that sociomaterial practice can give us a good theory view to interpret the ERP implementation. Next, this article will analyse three specific strategies to ensure the successful implementation of ERP based on case studies.

\subsection{Focus on the Interests Inscribed in the ERP software}

In language of Actor Network Theory, ERP is a kind of “Immutable mobile”. They inscribe the interests of various human agents and can be thought therefore to be a delegate that "speaks on their behalf." The enrolment of other actors in networks surrounding the new ERP requires that these actors adopt attitudes and actions congruent with those of the interests inscribed in the technology.

On the one hand, users should analyse the interest gap between the ERP and the status of the enterprise, so as to make clear the implementation of the focus and goals; on the other hand, it should be clear how to write the concepts and interests of the focus actors in the software.

\subsection{Using “Black box” to froze network element}

In order to increase the irreversibility of the network, the focus actors often use "Black box", such as signing the target responsibility book, signing the documents, signing contracts and agreements, and solidifying the master data and processes in the software, which are very useful in this case.

\subsection{Focus on the emergent network}

The focus actors should be clear that in the process of enrolment, in addition to the formal network, we can also make use of the emergent network. For example, theories of collective action and theories of cognition have played a great role in this case. In addition, the stability and risk of the current network can be analysed by the concept of centrality and connection strength of the network. For example, the lack of central degree of information transmission process will affect the efficiency of communication.

\section{Conclusion}

In this article, we argue that comprehensive use of these theories of ANT, Agential Realism and Multidimensional Networks will offer researchers the ability to visualize sociomaterial practice. This paper shows how to use ANT, Agential Realism and Multidimensional Networks to reveal the process of social change in the implementation of ERP in a case study. The goal is to provide theoretical and conceptual tools to help ERP implementers understand the social change process and their dynamic mechanism. This article gives a good sample of the study of sociomaterial practice at the empirical level.

\section{Acknowledgements}

Supported by Innovative School Project in Higher Education of Guangdong, China. Project 
Number: GWTP-BS-2014-26

\section{References}

[1] Perrow, C. (1967) A Framework for the Comparative Analysis of Organization. American Sociological Review, 32(2), 194-208.

[2] Barley, S.R. (1986) Technology as an occasion for structuring: evidence from observations of CT scanners and the social order of radiology departments. Administrative Science Quarterly, 31(1), 78-108.

[3] Leonardi, P.M. and S.R. Barley. (2008) Materiality and change: Challenges to building better theory about technology and organizing. Information \& Organization, 18(3), 159-176.

[4] Orlikowski, W.J. and S.V. Scott. (2008) 10 Sociomateriality: Challenging the Separation of Technology, Work and Organization. Academy of Management Annals, 2(1), 433-474.

[5] Leonardi, P.M. (2009) Crossing the Implementation Line: The Mutual Constitution of Technology and Organizing Across Development and Use Activities. Communication Theory, 19(3), 278-310.

[6] Pickering, A. and K. Guzik. (2008) The mangle in practice: science, society, and becoming, Duke University Press. 193-194.

[7] Leonardi, P.M. (2011) When flexible routines meet flexible technologies: affordance, constraint, and the imbrication of human and material agencies. Social Science Electronic Publishing, 35(1), 147-168.

[8] Mueller, B., U. Renken and G.V.D. Heuvel. (2016) Get Your Act Together: An Alternative Approach to Understanding the Impact of Technology on Individual and Organizational Behavior, ACM, 67-83.

[9] Jones, M. (2014) A matter of life and death: exploring conceptualizations of sociomateriality in the context of critical care, Society for Information Management and The Management Information Systems Research Center, 895926. 